\title{
The Effects of Parental Leave on Child Health and Postnatal Care: Evidence from Australia
}

\begin{abstract}
One of the arguments that is advanced in support of paid maternity leave policies is that the mother's time away from work, around childbirth, is expected to improve child health and development. However the research evidence on these links is scarce and, until recently, little was known about the link, if any, between child health and parental leave in particular. Using an extended random effects estimator to control for selection bias and unobserved heterogeneity, we employ micro-level data from the Parental Leave in Australia Survey, which is a nested survey of the Longitudinal Study of Australian Children, to examine the effects of parental leave on measures of child health and the provision of health inputs to the child. We found that parental leave around child birth was significantly associated with prolonged breastfeeding, up-to-date immunisation and other positive effects on some chronic health conditions such as asthma, bronchiolitis. For example, children of mothers who took an additional week of paid maternity leave have a lower probability of having asthma and bronchiolitis by 1.1 and 0.5 percentage points respectively. They are also slightly more likely to be breastfed until one monthand 6 months of age (2.1 and 0.6 percentage points, respectively).
\end{abstract}

Key words: parental leave, child health, postnatal care, Australia

JEL codes: I1, J5 


\section{Introduction}

One reason that is advanced for maternity leave is the workplace attachment for mother, yet the health of both the mother and the child may also be affected by the provision of maternity leave. The health production model (Grossman, 1972) and variants of it (see, for example, Ruhm, 2000; and Jacobson, 2000) provides a theoretical basis for hypothesising that maternity and paternity leave provisions may positively affect the health inputs-including parental time-that are supplied to young children. The limited literature that exists has either examined the relationship between maternity leave and child developmental outcomes, or the relationship between maternity leave and infant mortality rates overlooking the impacts of child's general health status and chronic conditions in particular. Another limitation in the research is that most of the studies have focussed on the USA (e.g.,Berger \& Waldfogel, 2004;Berger et al., 2005; Rossin, 2011;Huang \& Yang, 2014 among others), a few of them on some European countries (e.g.,Gregg et al., 2005; Haines \& Kintner, 2008;Dustmann \& Schonberg, 2012) and Canada (e.g., Baker \& Milligan, 2008b;Baker \& Milligan, 2010), no study to date has focussed on Australia, particularly on the impacts of parental leave on child health.A further difficulty with testing the association between maternity leave and child morbidity indicators (e.g., general health status and medical conditions) is that of controlling for unobserved factors that may affect both the availability of or decision to take maternity leave as well as the amount of time that parents dedicate to care for their children. The effects of maternity leave on children's health thus may be estimated with bias when these problems are ignored.

This study fills the gap in the literature by investigating effects of parental leave on various child health measures (e.g., general health status and the probability of having medical conditions) and indicators of postnatal care (e.g., breastfeeding and immunisation) using data from the Parental Leave in Australia Survey (PLAS). It also investigates the role of paternal leave as suggested by Gregg and Waldfogel (2005) on child health and postnatal care. The PLAS is a between-wave (Wave 1 and Wave 2) survey that was conducted in 2005 in conjunction with the Longitudinal Study of Australia Children (LSAC). We militate against the potential bias due to unobserved heterogeneity by using a rich random effect estimator that was proposed by Mundlak (1978) and extended by Contoyannis \& Li (2011). This study is, to the best of our knowledge, the first attempt to examine the relationship between parental leave and child health using household-level data in Australia. 


\section{Literature review}

\subsection{Parental leave and child health}

In a pioneering study on the effects of maternity leave, Winegarden \& Bracy (1995), used data from 17 OECD countries in four periods - 1959, 1969, 1979 and 1989 - and found that maternity leave contributed to reductions of the infant mortality rate. The marginal effects from their estimates suggest that an additional week of paid maternity leave was associated with a reduction in infant mortality of approximately 0.5 deaths per 1000 live births. Ruhm (2000) examined data for 16 OECD countries in the 1969-1994 periods and produced similar findings. Ruhm found that longer parental leave was associated with lower infant mortality rates (a 10-week increase in paid maternity leave was estimated to lead to 1-2 per cent reduction of the infant mortality rate). However, Ruhm's (2000) study did not include two important OECD countries: the United States and Japan. Ruhm (2000) also did not examine the effect of types of parental leave other than paid/job-protected parental leave. Tanaka (2005) extended the work of Ruhm (2000) to include the USA and Japan and updated the data set from 1994 to 2000. The author examined health outcomes other than the mortality rate and controlled for other social policies that were in effects during the study period and might also affect child health. Her results also showed that longer paid maternity leave was associated with lower infant mortality rates. In addition, paid maternity leave was associated with a statistically significantly lower probability of having a low birth weight child, but did not

affect the probability of immunisation against measles and diphtheria-tetanus-pertussis (DTP). Tanaka (2005) found no statistically significant effects of other types of leave (i.e., unpaid leave and other leave that was not job-protected) on infant mortality. On the contrary, using policy data for 185 UN member countries, Daku et al. (2012) found that full-time equivalent weeks of maternity leave is associated with higher probability of childhood vaccination rates.

Although most of the early studies of parental leave and child health have used aggregate data, there have been several studies since 2000 that have used micro-level data. Most of these studies have analyzed data from the National Longitudinal Survey of the Young (NLSY), which has been conducted as a nationwide longitudinal study in the United States since 1979. For example, Han et al. (2001), Waldfogel et al. (2002), Brooks-Gunn et al. (2002) and Ruhm (2004) used NLSY data to show that maternal employment in the first year of life is associated with adverse effects on child cognitive outcomes. These studies did not, however, address the question of whether maternal employment affects child development outcomes or indicators within the first year of life. To answer that question, Berger et al. (2005) focused on analysing 
the effects of mothers who return to work within 12 weeks of giving birth, using ordinary least squares (OLS) and propensity score matching, and found statistically significant reductions in both breastfeeding and immunisation: children whose mothers returned to work early were less likely to have regular health check-ups and were less likely to be breastfed. Gregg et al. (2005) also investigated the issue of early maternal employment and child outcomes in the UK and found that a return to full-time employment within 18 months after giving birth resulted in poorer cognitive outcomes for children.

In contrast to the above literature that examined the effects of parental leave on child cognitive and non-cognitive development, some recent literature (e.g.,Rossin, 2011;Cooklin et al., 2012; Dustmann \& Schonberg, 2012 and Huang \& Yang, 2014) has examined different dimensions of parental leave. It is indeed very important to examine the impacts of paid parental leave on breast feeding in particular, as there is a strong evidence on the impacts of infant breastfeeding practices on later life outcomes (see for example, Kuhn et al., 2006; Reid, 2002; Kintner, 1988; Woodbury, 1926; Haines \& Kintner, 2008 ).

Baker and Milligan (2008b) examined the effects of maternity leave reforms in Canada on the decision to breastfeed and on the health of the mother and the child. For children 7-12 months of age, their results confirmed that the extension of maternity leave increased the duration of breastfeeding. The authors also found that extended maternity leave created beneficial effects on the incidence of asthma, allergies and chronic conditions, however, these effects did not persist as children grew older. In a US study, Rossin (2011) found that maternity leave increased birth weight and decreased the probability of a premature birth and infant mortality for college-educated and married mothers. Using a small sample of eligible women, an Australian study by Cooklin et al. (2012) found that paid parental leave supports breastfeeding and mother-infant relationship. Huang \& Yang (2014) examined paid maternity leave and breastfeeding practice before and after California's implementation of the nation's first paid family leave program. They found similar results as Cooklin et al. (2012) about breastfeeding; they reported a 3-5 percentage points increase in exclusive breast feeding, if mother took paid maternity leave.

Some recent studies, though, have produce results that are in contrast to studies reviewed above. Dustmann \& Schonberg (2012) found no evidence that extensions of unpaid and paid maternity leave in Germany have improved children's health and developmental outcomes. Baker \& Milligan (2010) found no significant impacts of a recent increase in maternity leave from 6 months to one year in Canada for early childhood development. Rasmussen (2010) also found that increase in birth related leave in Sweden has no measurable effect on children's long term education outcomes.

Thus, while much of the literature suggests that maternity leave is associated with improved child health and development outcomes, this has not universally been found to be true. The literature to date 
thus raises some interesting questions about the benefits of maternity leave for the children of (in)eligible mothers. These include not only the question of whether maternity leave per se has beneficial effects on the health and development of children, but also if and when diminishing returns to child health production set in. If, indeed, child health is positively influenced by maternity leave this effect should be included in the calculus of the social net benefits that may be associated with maternity leave.

\subsection{Parental leave in Australia}

Our study examines the relationship between maternity leave and indicators of child health for a period when Australia had not introduced a universal paid parental leave. Indeed, Australia was one of the last countries in the OECD to introduce universal paid parental leave, under a scheme called Paid Parental Leave Scheme, on 1 January 2011. Although paid maternity leave was introduced for public sector employees in the 1970s, unpaid parental leave has been an entitlement for permanent private sector employees with at least 12 months of continuous employment before the birth of the child since 1979 (Whitehouse et al., 2005). Access to paid parental leave in the private sector was less common and, as a result, about 60 per cent of women who work in Australia did not have access to paid maternity leave (Baird, 2004) prior to 2011.

Apart from the historical lack of a universal paid parental leave provision, Australia also suffers from a shortage information on the prevalence of parental leave. For example, the Human Rights and Equal Opportunity Commission (HREOC) revealed that Australia lacks information on basic issues such as the proportion of employees that is eligible for parental leave, the number of women who take paid and unpaid maternity leave and the return-to-work activities of women, following childbirth(HREOC, 2002). According to Whitehouse et al. (2007a), the main source of information about parental leave in Australia to date has been state-level surveys on caring and responsibilities that have been undertaken by the Australian Bureau of Statistics ${ }^{1}$ with the exception of the "Maternity leave in Australia: employee and employer perspectives" survey conducted by the Australian Institute of Family Studies in 1986 (Glezer, 1988).

The Parental Leave in Australia Survey (PLAS) was an attempt to fill the data gap. The preliminary findings by Whitehouse et al. (2006; 2007a) revealed that 34 per cent of employed mothers and 20 per cent of employed fathers took paid leave prior to the birth of their child. However, the most important

\footnotetext{
${ }^{1}$ For example, Managing Caring Responsibilities and Paid Employment: New South Wales (Cat N0. 4903.1) and Queensland (Cat No. 4903.3), Managing Care and Work, New South Wales, Oct 2005 (Cat No. 4912.1), and Balancing Work and Caring Responsibilities, Tasmania, Oct 1999 (Cat No. 4903.6)
} 
form of leave for mothers is unpaid maternity leave (53 per cent) whilst for fathers it was paid holiday leave (46 per cent). The most common choices of maternity leave were 6 weeks and 52 weeks for paid and unpaid maternity leave, respectively (Whitehouse et al., 2008). It is not surprising, therefore, that 46 per cent of mothers who worked for an employer in the past 12 months prior to birth stated that they would like to take more leave and would do so if they had more paid leave. Interestingly, Whitehouse et al. (2008) found that compared to those take leave of 40 to 52 weeks, people who take 53 weeks of leave or more would be less satisfied if they take further leave (although this result was not statistically significant).

Baxter (2009) examined the determinants of returns to work by mothers using PLAS data. A major difference of this study, compared to Whitehouse et al. (2008), was its focus on the use of leave rather than the entitlement to leave. The author showed that most mothers returned to work when their child was 12 months old, and this is likely to be associated with the 12 months of unpaid ("job-protected") leave available for those who were permanently employed before childbirth. Pre-birth employment type was also an important determinant of the decision to return to work. Baxter (2009) also found that, at 18 months, those who were most likely to return to work were self-employed ( 84 per cent), permanent employees (76 per cent), contract employees (64 per cent) and casual employees (58 per cent). However, at earlier time points (e.g., nine and 12 months), there were little differences in the likelihood of return to work by employment types prior to childbirth.

Most previous studies use aggregate data due to the scarcity of appropriate unit record data. The PLAS represents the most comprehensive unit record data set available in Australia that is amenable to work of this kind. Few previous studies have examined the effects of paternity leave by fathers (Gregg \& Waldfogel, 2005). This paper aims to shed light on this issue with an Australian application. In addition, it produces new empirical results based on the PLAS on the relationship between paid maternity leave, breastfeeding, and child health.

\section{Methodology}

The relationship between child health and maternity leave can be represented in an extended Grossman (1972) model of the kind used by Ruhm (2000) and others (e.g., Jacobson, 2000; Khanam et al., 2009), in which parents maximise their utility, which is described by a function $U(H, X)$, where $H$ is child health, and $X$ is other consumption. The parents face a time constraint $T=R+L+V$ where $R, L$ and $V$ are time for work, leave and produce non-market outputs (e.g., preparing home meals); and a budget constraint 
$Y=P_{m} M+P_{x} X=w R+s L+N$, where $M$ is the medical care; $P_{m}$ and $P_{x}$ are prices of $M$ and $X$, respectively; $w$ is the wage rate, $s$ is the maternity leave payment, and $N$ is the non-earned income. The health of the child is produced by the production function $H(B, M, L+V, \varepsilon)$ where $B$ is the baseline health level and $\varepsilon$ is a stochastic error. According to this formulation, the duration of maternity/paternity leave affect the amount of time available to care for children, which in turn affects the production of child health.

Generally, the health production model by Grossman (1972) stated that individuals are born with an initial stock of health that depreciates over time; and the current health stock depends on the previous health stock, depreciation and health investment during the study period. The initial health stock of children is affected by factors such as biological inheritance and health investments during pregnancy, including medical and other (e.g., dietary) inputs. Postnatal health inputs, including market and nonmarket inputs may be affected by a mother's eligibility to take paid maternity leave. Paid maternity leave may affect child health by increasing the maternity time available to care for young children. For example, paid maternity leave may reduce the time and other costs of breastfeeding, which may in turn can lead to better infant (and perhaps child and adult) health. Paid maternity leave may also allow parents to spend more time taking care of their infants, which may lead to the establishment of stronger bonds between children and parents. Yet the influence of paid maternity leave of child health is also theoretically ambiguous. For example, Ruhm (2000) suggested that paid maternity leave may induce women to work early in their pregnancy in order to qualify for the paid leave, hence reducing the time available for early pregnancy care.

Based on the conceptual framework above, the relationship between maternity leave and child health is presented as:

$$
H_{i t}=\beta_{0}+\beta_{1} L_{i t}+\beta_{2} H_{i, t-1}+\beta_{3} X_{i t}+\alpha_{i}+\varepsilon_{i t}
$$

where $H_{i t}$ is a measure of child health and other outcomes of interest (e.g., breastfeeding, immunisation status, and the incidence of having medical conditions) of household ${ }^{2} i$ in period $t, X_{i t}$ is a set of exogenous household and child characteristics, $L_{i t}$ is a set of variable representing maternity leave, and $\varepsilon_{i t}$ is the error term. The inclusion of $H_{i, t-1}$ - the lag of child health and some development outcomes (e.g., medical conditions) - is based on the health production model by Grossman (1972). The choice of estimator for

\footnotetext{
${ }^{2}$ This formulation is for convenience of the LSAC data (will be discussed in more detailed in Section 4), where one child is interviewed in a household. In case of multiple children studied in a households, child-specific indicator is required.
} 
Equation (1) is selected according to the outcome of interest, leading us to estimate ordered probit, probit and ordinary least squares for ordered, binary and continous response items.

One potential problem with estimating Equation 1 is that there may be a correlation between $L_{i}$ and some unobserved individual and household characteristics $\left(\alpha_{i}\right)$ that affect both child health and the amount of maternity leave (i.e., $L_{i}$ and $\varepsilon_{i}$ are correlated). Thus, an application of ordinary least squares to estimate Equation 1 may produce estimates that are biased and inconsistent.

The endogeneity problem can may be addressed by regressing the maternity leave indicator on a set of exogenous variables, $Z_{i t}$, that are correlated with $L_{i t}$ but are uncorrelated with $\varepsilon_{i t}$ (i.e., using instrumental variables), except via their effect on $L_{i t}$. That is, one first estimates the first-stage equation:

$$
L_{i t}=\lambda_{0}+\lambda_{1} Z_{i t}+\lambda_{2} X_{i t}+\epsilon_{i t}
$$

and then replaces $L_{i t}$ in Equation 1 with the predicted values of it obtained from Equation 2. However, it seems obvious that most variables that determine eligibility for paid maternity leave (e.g., education, age, employment characteristics of mothers) also affect the variables of primary interest (e.g., child health and the incidence of breastfeeding).

An alternative way to address the unobserved heterogeneity issue is to control as much as possible for observed heterogeneity (i.e., the 'mopping-up' approach, see for example, Gregg et al., 2005). Owing to the richness of the LSAC data set, the application of this approach is possible in our study. In particular, we construct a comprehensive set of variables that may affect child development outcomes (e.g., health status), including socio-economic and demographic characteristics of the child and their family, and the characteristics of their neighbourhoods. However, even the richness of the available set of covariates does not entirely acquit us of the effects of unobserved heterogeneity (Murnane \& Willett, 2010). Thus it is still necessary to try to address the suspected endogeneity problem by using other analytical approaches.

The two approaches that are now commonly used to control for unobserved individual characteristics using panel data include a fixed-effects estimator (Chamberlain, 1980; Ferrer-i Carbonell \& Frijters, 2004; Carro, 2007; Jones \& Schurer, 2011), and a random-effects estimator (Mundlak, 1978; Contoyannis et al., 2004; Contoyannis \& Li, 2011). The former approach eliminates the individual unobserved heterogeneity factor $\alpha_{i}$ via means such as first differencing whilst the latter assumes that $\alpha_{i}$ is uncorrelated with other covariates. Unfortunately, the fixed effect approach is not applicable in this study for three reasons. First, the value of the variable of primary interest-maternity leave-does not vary across waves because data on 
maternity leave are only available in Wave 1.5 of the PLAS, from 2005. Second, the assumption of fixed effects for children-who, in our sample are very young and are hence developing-would seem not to be theoretically defensible. Third, the standard treatment of first differencing cannot be used to address the endogeneity problem because a difference in the lag of health $\left(H_{i, t-1}-H_{i, t-2}\right)$ on the right-hand side of (1) is correlated with the difference in the error term $\left(\varepsilon_{i t}-\varepsilon_{i, t-1}\right)$ (see, e.g., Greene, 2008). Thus, we implement the so-called "rich" random effect approach pioneered by Mundlak (1978) and extended by Contoyannis \& $\mathrm{Li}$ (2011), in which it is assumed that unobserved individual effects are linearly correlated with between-wave averages of other covariates:

$$
\alpha_{i}=\alpha_{0}+\alpha_{1} H_{i, 1}+\alpha_{2} \bar{X}_{i}+u_{i}
$$

where $H_{i, 1}$ is the value of $H_{i t}$ in Wave 1 , representing the initial value and $\bar{X}_{i}$ is the across-wave average of exogenous variables and $u_{i}$ is the random noise. Compared with the assumption of the standard random effects estimator (i.e., $\alpha_{i}$ is uncorrelated with $X_{i}$ ), the "rich" random effects estimator make a relatively weaker assumption that $\alpha_{i}$ is correlated with $\bar{X}_{i}$. Our maintained hypothesis is that $\bar{X}_{i}$ captures "permanent" characteristics of the households/individuals whilst the $X_{i t}$ variables are affected by contemporaneous shocks. A number of other panel data studies (Contoyannis et al., 2004; Propper et al., 2007; Contoyannis \& Li, 2011) have also treated the household's time-averaged income as "permanent income", while using current income to represent transient income shocks. Similarly, one may also argue that the average hours work of a person over time capture unobserved characteristics (e.g., ability) that are relevant to labour force participation, while contemporaneous work hours may reflect time-specific shocks (e.g., due to macro-economic conditions) to employment.

\section{Data and variable selection}

\subsection{Data sources}

This study uses data from the Parental Leave Australia Survey (PLAS), which was conducted in 2005, nested in the between-wave mail-out survey that occurred between Wave 1 (conducted in 2004) and Wave 2 (conducted in 2006) of the nationally-representative Longitudinal Study of Australian Children (LSAC). The latter panel includes information on approximately 10,000 children (one child per household) including around 5000 infants aged 0-1 years in 2004 and around 5000 children aged 3-4 years in the same 
period (AIFS, 2007). The LSAC will continue until at least 2018 at intervals of one survey wave every two years. The PLAS targeted the infant cohort (i.e., B-cohort) of the LSAC, which included children born between March 2003 and February 2004, and thus contains data contain collected proximate to the birth of infants in this cohort. The sampling frame of the LSAC was constructed using the Medicare Australia database, which essentially included all children of the sampling age in Australia. The recruitment process was based on the sampling frame of 5107 infants included in Wave 1 of the LSAC (Soloff et al., 2005), from which the PLAS sent 5061 questionnaires and received 3573 responses, which constituted a response rate of 70.6 per cent (Whitehouse et al., 2007a). The PLAS questionnaires include questions in three main components: the work history of parents, maternity leave experience and return-to-work. Other information of interest, such as child health, and further household and child characteristics were obtained from the first five waves of LSAC data, conducted in 2004, 2006, 2008, 2010 and 2012. Since the maternity leave survey was conducted with only the infant cohort (B cohort) and only around half of households reported maternity leave data, our final data set includes observations in the first five waves of LSAC with the sample in wave $1,2,3,4$, and 5 are $1693,1654,1611,1593$ and 1550 , respectively.

\subsection{Choice of variables}

We explore the effects of parental leave on selected outcomes of interest: parental reports of the general health status of their child, the duration of breastfeeding (measured as whether the child was breastfed at one month and at six months), and the probability of having (the physician-diagnosed conditions) asthma and bronchiolitis. We examine the effect of parental leave on child health outcomes using two sets of individual and household characteristics, which refer to as the "basic" and "extended" set of controls. The selection of these variables was based both on health production theory and the related applied literature (Grossman, 1972; 2000; Ruhm, 2000; and Jacobson, 2000) as well as the data available from the LSAC. The basic set of covariates include age and gender of the child, previous health status of the child household size, log of CPI-adjusted average family income (proxied for permanent income), age and education status of mother and father. The extended set of controls include variables in the basic covariate set plus parental physical and mental health, indicators of parenting style (proxied by the frequency of showing affection and express hapiness such as hugs and kisses toward children), and lifestyle factors including participation in physical activities. As discussed in Khanam et al. (2009), parental health was the dominant determinant of child health in LSAC. Extended covariates are used as an attempt to control for unobserved heterogeneity in addition to our use of random effects model. 


\subsection{Descriptive statistics}

The descriptive statistics in Table 1 suggest a systematic difference between households who did not report any maternity leave and those who took at least some leave during child birth. In particular, households that did not take paid maternity leave (PML) and paid paternity leave (PPL) have lower income, lower parental education level, lower parental health, are more likely to identify as being an Aboriginal or Torres Strait Islander (ATSI) background, and are less likely to have both biological parents co-residing. For example, the average yearly household incomes of those that took PML and PPL are $\$ 96,500$ and $\$ 93,195$ respectively, while the average figures of those who did not take PML and PPL are $\$ 81,000$ and $\$ 84,000$, respectively. The average parent-reported health status of children was also better-as indicated by a lower score in the 5 -point Likert scale-among households where mothers took PML compared with who did not take any maternity leave. There is, however, no statistical significant difference in the health of children whose fathers took PPL and of those who did not.

Table 1 also shows that PML and PPL only contribute to small portion of total time that parents took off work in connection with a child's birth. For example, those who did not have PML took 34 weeks of leave (e.g., annual leave, sick leave and unpaid leave) in connection with their child's birth, which is approximately the amount of other leave that mothers with PML took in addition to PML (i.e., their average total leave was 43 weeks and average PML of 11 weeks, hence the average unpaid leave is $43-11=32$ weeks). However, fathers who took PPL appear to take less the other leave than those who did not take PPL as the total amount of leave during child birth for the two groups are 16 and 13 weeks, respectively (including 7 weeks of PPL for the former group). One possible reason for this is that PPL is the privilege reserved only for those work at large organisations, and labour market divisions and career pressure are barriers to fathers taking extended leave in connection with their child's birth (Whitehouse et al., 2007b). In addition, the total amount of leave that fathers took was not statistically significantly different between families where mothers took PML and those who did not. Curiously, the incidence of having asthma or bronchiolitis is higher for children whose father took PPL while the reverse is true for children whose mothers took PML. Observed child health inputs, such as immunisation and breastfeeding, appear to be positively associated with both PML and PPL. This motivates us to consider estimating the effects of PML and PPL individually, but to test for interaction effects for these two types of leave. 
Table 1: Descriptive statistics

\begin{tabular}{|c|c|c|c|c|}
\hline Variables & PML & No-PML & PPL & No-PPL \\
\hline \multicolumn{5}{|l|}{ Basic Covariates } \\
\hline Duration of PML (weeks) & 43.713 & 36.545 & $\# 40.220$ & 41.179 \\
\hline All maternity leave (weeks) & 11.296 & 0.000 & $\# 11.180$ & 11.507 \\
\hline Duration of PPL (weeks) & \#7.145 & 7.839 & 7.356 & 0.000 \\
\hline All paternity leave (weeks) & \#15.273 & 15.922 & 17.939 & 14.198 \\
\hline Child's age (Months) & \#32.916 & 32.777 & $\# 32.797$ & 32.892 \\
\hline Gender of the child ( $1=$ male $)$ & $\# 0.493$ & 0.518 & \#0.495 & 0.517 \\
\hline $\begin{array}{l}\text { Household annual income }(\$, 2002 \\
\text { price) }\end{array}$ & 91,772 & 77,353 & 95,345 & 85,422 \\
\hline Mother's age (years) & 34.692 & 33.655 & 34.204 & 33.935 \\
\hline Father's age (years) & 36.599 & 35.847 & $\# 35.677$ & 35.987 \\
\hline Mother completed year 12 ( $1=$ yes $)$ & 0.883 & 0.779 & 0.865 & 0.815 \\
\hline Mother has a graduate degree ( $1=$ yes $)$ & 0.470 & 0.275 & 0.440 & 0.355 \\
\hline $\begin{array}{l}\text { Mother has a postgraduate degree } \\
(1=\text { yes })\end{array}$ & \multicolumn{3}{|c|}{$(1=$ yes $)$} & 0.121 \\
\hline Father completed year 12 (1=yes) & 0.676 & 0.556 & 0.739 & 0.636 \\
\hline Father has a graduate degree (1=yes) & 0.301 & 0.187 & 0.330 & 0.240 \\
\hline $\begin{array}{l}\text { Father has a postgraduate degree } \\
(1=\text { yes })\end{array}$ & 0.111 & 0.069 & 0.144 & 0.088 \\
\hline Household size & 3.979 & 3.879 & \#3.917 & 3.951 \\
\hline English spoken at home (1=yes) & $\# 0.936$ & 0.929 & 0.946 & 0.928 \\
\hline $\begin{array}{l}\text { Aboriginal and Torres Strait Islanders } \\
(1=\text { yes })\end{array}$ & 0.007 & 0.019 & 0.009 & 0.011 \\
\hline $\begin{array}{l}\text { Both parents are at home }(1=\text { yes }) \\
\text { Extended Covariates }\end{array}$ & 0.942 & 0.932 & 0.967 & 0.967 \\
\hline Housing condition $(1=$ clean $)$ & $\# 0.957$ & 0.954 & 0.948 & 0.965 \\
\hline Mother's health ( $1=$ Excellent/good) & $\# 0.700$ & 0.679 & 0.697 & 0.682 \\
\hline Father's health $(1=$ good $)$ & $\# 0.614$ & 0.593 & 0.646 & 0.593 \\
\hline Depression scale of mother ${ }^{1}$ & \#4.538 & 4.522 & $\# 4.527$ & 4.529 \\
\hline Depression scale of father ${ }^{1}$ & $\# 4.483$ & 4.499 & $\# 4.489$ & 4.499 \\
\hline Mother's parenting style ${ }^{2}$ & $\# 0.831$ & 0.826 & $\# 0.813$ & 0.828 \\
\hline Father's parenting style ${ }^{2}$ & $\# 0.650$ & 0.622 & $\# 0.660$ & 0.627 \\
\hline Mother smoked during pregnancy & 0.073 & 0.110 & 0.066 & 0.098 \\
\hline Mother was a frequent smoker & 0.337 & 0.404 & 0.320 & 0.386 \\
\hline Father was a frequent smoker & $\# 0.394$ & 0.426 & 0.373 & 0.418 \\
\hline Mother was a heavy drinker & $\# 0.033$ & 0.027 & $\# 0.030$ & 0.028 \\
\hline Father was a heavy drinker & 0.033 & 0.049 & 0.021 & 0.042 \\
\hline \multicolumn{5}{|l|}{ Outcome Variables } \\
\hline Child health ( $1=$ excellent, $5=$ poor $)$ & 1.515 & 1.577 & $\# 1.533$ & 1.558 \\
\hline Diagnosed with asthma ( $1=$ yes $)$ & 0.122 & 0.162 & $\# 0.147$ & 0.145 \\
\hline Diagnosed with bronchiolitis (1=yes) & $\# 0.101$ & 0.114 & 0.138 & 0.099 \\
\hline Fully immunized ( $1=$ yes) & 0.959 & 0.947 & $\# 0.951$ & 0.956 \\
\hline Breastfeeding at 1 month ( $1=$ yes $)$ & 0.897 & 0.838 & 0.906 & 0.849 \\
\hline Breastfeeding at 6 months $(1=$ yes $)$ & 0.678 & 0.557 & 0.679 & 0.608 \\
\hline
\end{tabular}

Note: $P M L=$ Paid maternity leave; PPL=Paid paternity leave; \#t-test for the mean difference of continous variables (and Wilcoxon test for the median differences of categorical variables) between those who took PML/PPL and others was not significant at $5 \%$.

${ }^{1}$ means of 5-point Likert scale (1=all the time, 5=none) questions about the frequency of feeling: nervousness, hopeless, restless, sadness, worthless and lack of energy;

${ }^{2}$ mean of 5-point Liker scale questions (1=never, 5=always) about the frequency of showing affection (e..g, hug) children and express happiness to children 


\section{Results and discussion}

\subsection{Effects on children's general health status}

Table 2 presents the main results that are derived by estimating child health production models by a random effects ordered probit model on the LSAC data. The left-hand side of Table 2 contains three models that were specified with the basic set of covariates, and the right-hand side contains the results of estimating those models on the extended set of covariates. Three models are presented in each instance: a model in which only paid parental leave is included, measured in weeks; a model in which paternal leave plus also all other types of leave (e.g., recreation leave, sick leave, long-service leave) are included, measured in weeks; and an indicator model in which the leave variable is a binary variable equal to one if either parent took paid parental leave and zero otherwise .

Table 2 shows that mother's leave is not significantly associated with the probability of better child health, whereas father's leave has a significant effect on child's general health status; the effect of father's leave is 1.6 and 0.7 percentage points for paid leave and all types of leave respectively. However, the effect of father's leave does not hold when extended covariates are used. The results in Table 2 consistently suggest that the child's current reported health state is strongly related to its reported health states in previous years. The past health status and the initial level of health (proxied by health status at Wave 1) significantly determined the current health status, in both basic and extended covariates. In particular, the lag of health status is significantly and positively associated with current health status. Thus, a child who was reported as having an excellent health in the previous survey wave is more likely to be reported to be at that level of health in the current period. Meanwhile, compared with those who were reported "excellent" initial health status (i.e., baseline heatlh=1), children with other baseline health states have significantly poorer current health status. Perhaps surprisingly, though, children who were reported to have poor health in Wave 1 (baseline health $=5$ ) were not significantly more likely to have poorer health in the current period, compared with those having excellent baseline health despite having the expected positive sign (i.e., poorer health than the reference group with excellent health). One possible reason is due to the small observations of children in this group: only 16 children ( 0.3 per cent of the sample) were reported to be in poor health at baseline.

Among the variables that were added in our extended set of covariates, the health status of the child's mother was also significantly associated with child's reported health state. In particular, children of mother who was reported to be in good health status were also significantly more likely to have good 
health. This story is consistent with analyses of all leave types, whether paid or unpaid.

Table 2: Effects of parental leave on child general health status (random effects ordered probit model)

\begin{tabular}{|c|c|c|c|c|c|c|}
\hline \multirow{3}{*}{$\begin{array}{l}\text { Selected } \\
\text { variables }\end{array}$} & \multicolumn{3}{|c|}{ Basic covariates } & \multicolumn{3}{|c|}{ Extended covariates } \\
\hline & Paid parental & All leave ${ }^{a}$ & No leave & Paid parental & All leave ${ }^{a}$ & No leave \\
\hline & \multicolumn{2}{|l|}{ leave } & \multicolumn{4}{|c|}{ leave } \\
\hline Mother's leave (weeks) & -0.001 & 0.002 & & 0.001 & 0.002 & \\
\hline Father's leave (weeks) & $*_{0}^{*} 013$ & $* 0.007$ & & 0.011 & 0.006 & \\
\hline Mother $\times$ Father leave & $*_{-0} 0.002$ & $*_{-0} 0.000$ & & -0.001 & -0.000 & \\
\hline No parental leave $(1=$ yes $)$ & \multicolumn{3}{|r|}{$* * 0.081$} & \multicolumn{3}{|r|}{0.027} \\
\hline Log of household income & -0.102 & -0.011 & $* * *_{-} 0.129$ & 0.131 & 0.134 & -0.039 \\
\hline Lag of health & $* * * 0.19$ & $* 0.081$ & $* * * 0.120$ & $* * * 0.142$ & $* * * 0.142$ & $* * * 0.191$ \\
\hline Initial (Wave 1) health $=2$ & $* * * 0.350$ & $* * * 0.360$ & $* * * 0.447$ & $* * * 0.208$ & $* * * 0.212$ & $* * * 0.251$ \\
\hline Initial health $=3$ & $* * * 0.797$ & $* * * 0.807$ & $* * * 0.714$ & $* * * 0.522$ & $* * * 0.526$ & $* * * 0.394$ \\
\hline Initial health $=4$ & $* * * 0.681$ & $* * * 0.702$ & $* * * 0.556$ & 0.275 & 0.286 & *0.184 \\
\hline Initial health $=5$ & 0.854 & 0.787 & 0.215 & 0.236 & 0.231 & -0.458 \\
\hline \multicolumn{4}{|l|}{$\begin{array}{l}\text { Mother is in good health } \\
\text { (1=yes) }\end{array}$} & $* * *_{-} 0.322$ & $* * *-0.325$ & $* * *-0.219$ \\
\hline \multicolumn{7}{|c|}{$\begin{array}{l}\text { Note: Basic Covariates include child's age, gender, child's previous health status, family income, parents' age and education, } \\
\text { family income, household size, English spoken at home, Aboriginal and Torres Strait Islanders status, presence of both parents } \\
\text { at home; Extended covariates include basic covariates plus parents' mental and physical health, parenting style. Other covariates } \\
\text { are mostly insignificant and are not reported for brevity. Significance levels: *** }=1 \%, * *=5 \% \text { and } *=10 \% ; \text { a all leave includes } \\
\text { paid parental leave, unpaid parental leave, recreation leave, long service leave, sick leave and other leave taken around childbirth. } \\
\text { To interpret the coefficient as marginal effects one would need to multiply them with the probability density function, which is } \\
\text { less than one, of the interested outcomes. Thus, the parameters can be loosely interpreted as the upper bound of the marginat } \\
\text { effects. }\end{array}$} \\
\hline
\end{tabular}

Since health status of children is reported in 5-points Likert scale, we therefore appied the extended random effects ordered probit regressions (Son, Pls check whether this sentence is ok?/RK 19 Aug15). Coefficients are difficult to interpret directly, we use predicted probability of each health status using results from Table 2. The relationship between self-reported health status $(H)$ and the latent variable health $\left(H^{*}\right)$ is presented as

$$
H= \begin{cases}1 \text { if } \quad-\infty \leq H^{*} \leq \mu_{1} \text { (Excellent) } \\ 2 \text { if } \quad \mu_{1} \leq H^{*} \leq \mu_{2} \text { (Very good) } \\ 3 \text { if } \quad \mu_{2} \leq H^{*} \leq \mu_{3} \text { (Good) } \\ 4 \text { if } \quad \mu_{3} \leq H^{*} \leq \mu_{4} \text { (Fair) } \\ 5 \text { if } \quad \mu_{4} \leq H^{*} \leq \infty \text { (Poor) }\end{cases}
$$

Where $\mu_{s}$ are referred to as "cut-off" points to be estimated. Thus, the probability that a child to be in particular observed health state equals to the probabilty that latent health value takes a value between two cut-off points. 


$$
\operatorname{Pr}(H)=\left\{\begin{array}{l}
1=\Phi\left(\mu_{1}-X \beta\right) \\
2=\Phi\left(\mu_{2}-X \beta\right)-\Phi\left(\mu_{1}-X \beta\right) \\
3=\Phi\left(\mu_{3}-X \beta\right)-\Phi\left(\mu_{2}-X \beta\right) \\
4=\Phi\left(\mu_{4}-X \beta\right)-\Phi\left(\mu_{3}-X \beta\right) \\
5=1-\Phi\left(\mu_{4}-X \beta\right)
\end{array}\right.
$$

where $\Phi$ is the cumulative distribution function and $X \beta$ represent the linear prediction from estimating Equation (1). Since the prediction of marginal effects will produce probability of five self-reported health outcomes per estimator, we focus on the effects of paid parental leave only. The relationship between predicted probabilities of health status and the linear prediction from ordered probit extended random effects estimators show that the probability of the child being reported to be in excellent health status declines while the probability of reporting other health states increases(see Figure 1). When only a basic set of covariates is used, at the mean of linear prediction (-1.15), the probabilities of excellent, very good, good, fair and poor health are 53.5, 40.3, 5.7, 0.6 and 0.1 percent, respectively ${ }^{3}$. Thus, based on Table 2, the marginal effects for both mother and father of one more week of paid leave during child birth is a 0.002 reduction in the mean prediction. This corresponds to a $0.05 \%$ increase in the probability of reporting excellent health and decreases in the probability of having very good health of $0.03 \%$, good health by $0.01 \%$ and other health categories by very small margins ${ }^{4}$. When a comprehensive set of covariates are used, the predicted probability of health categories at the mean of linear prediction $(-2.1)$ are $57.1,34.8$, 6.8, 1.1 and 0.2 percent for excellent, very good, good, fair and poor, respectively. Among the other parameters of this model, the effects of mothers being in good health is is a 0.32 reduction in the linear prediction, which is also associated with a $0.3 \%$ increase in the probability of having excellent health and reduction in the probability of having very good health by $0.2 \%$, good health by $0.1 \%$, and with the probabilities of being in other health states virtually unchanged.

\subsection{Effects on chronic conditions and postnatal care}

This section examines the effects of parental leave on the probability that children were diagnosed with asthma, bronchiolitis, and were fully immunised or breastfed. Our results show that maternity leave has significant effects on asthma, bronchiolitis, and breastfeeding at one and six months. In particular, the probability that a child was diagnosed with asthma and bronchiolitis reduced by 0.5 and 1.1 percentage points if his/her mother took longer maternity leave. This finding is in line with our theoretical prediction

\footnotetext{
${ }^{3}$ For brevity we don't present full summary tables of margial effects, probabilities of health status and linear prediction. These detailed results can be made available from the authors upon request.

${ }^{4}$ These probabilities are read from the selective marginal effects in Table 3 but one can also see the rough probabilities by reading off Figure 1: moving the linear prediction from -1.15 by 0.002 to the left.
} 
Table 3: Marginal effects of Paid parental leave (percent)

\begin{tabular}{|c|c|c|c|c|c|}
\hline Models/variables & Excellent & Very good & Good & Fair & Poor \\
\hline \multicolumn{6}{|l|}{ Basic covariates } \\
\hline Paid maternity leave (weeks) & 0.02 & -0.01 & -0.01 & 0.00 & 0.00 \\
\hline Paid paternity leave (weeks) & -0.40 & 0.24 & 0.12 & 0.03 & 0.00 \\
\hline PML * PPL & 0.05 & -0.03 & -0.01 & 0.00 & 0.00 \\
\hline Log of household income & 2.30 & -1.42 & -0.72 & -0.15 & -0.01 \\
\hline Mother completed Year12 & 0.50 & -0.31 & -0.16 & -0.03 & 0.00 \\
\hline Mother have graduate degree & 3.67 & -2.29 & -1.14 & -0.23 & -0.01 \\
\hline Mother has postgraduate degree & 3.28 & -2.07 & -1.00 & -0.20 & -0.01 \\
\hline Fater completed Year12 & -0.86 & 0.54 & 0.27 & 0.06 & 0.00 \\
\hline Father have graduate degree & 4.21 & -2.65 & -1.29 & -0.26 & -0.01 \\
\hline Father has postgraduate degree & 5.31 & -3.42 & -1.57 & -0.31 & -0.01 \\
\hline Household size & 3.00 & -1.85 & -0.94 & -0.19 & -0.01 \\
\hline English spoken at home & 11.19 & -6.15 & -4.03 & -0.96 & -0.05 \\
\hline ATSI status & -3.87 & 2.34 & 1.25 & 0.27 & 0.01 \\
\hline Both parents at home & 3.82 & -2.27 & -1.26 & -0.27 & -0.01 \\
\hline Housing condition $($ clean $=1)$ & 2.64 & -1.59 & -0.86 & -0.18 & -0.01 \\
\hline \multicolumn{6}{|l|}{ Comprehensive covariates } \\
\hline Paid maternity leave (weeks) & -0.04 & 0.02 & 0.01 & 0.00 & 0.00 \\
\hline Paid paternity leave (weeks) & -0.25 & 0.15 & 0.08 & 0.02 & 0.00 \\
\hline $\mathrm{PML} * \mathrm{PPL}$ & 0.03 & -0.02 & -0.01 & 0.00 & 0.00 \\
\hline Log of household income & 2.80 & -1.68 & -0.88 & -0.22 & -0.01 \\
\hline Mother completed Year12 & 3.62 & -2.12 & -1.18 & -0.31 & -0.01 \\
\hline Mother have graduate degree & 4.15 & -2.51 & -1.30 & -0.33 & -0.01 \\
\hline Mother has postgraduate degree & 6.81 & -4.29 & -2.03 & -0.48 & -0.02 \\
\hline Fater completed Year12 & -1.12 & 0.67 & 0.35 & 0.09 & 0.00 \\
\hline Father have graduate degree & 1.99 & -1.21 & -0.62 & -0.16 & -0.01 \\
\hline Father has postgraduate degree & 6.85 & -4.33 & -2.02 & -0.48 & -0.02 \\
\hline Household size & 2.49 & -1.50 & -0.79 & -0.20 & -0.01 \\
\hline English spoken at home & 10.55 & -5.68 & -3.73 & -1.08 & -0.05 \\
\hline ATSI status & -15.26 & 7.54 & 5.79 & 1.85 & 0.09 \\
\hline Both parents at home & 2.61 & -1.53 & -0.85 & -0.22 & -0.01 \\
\hline Housing condition $($ clean $=1)$ & 2.04 & -1.20 & -0.66 & -0.17 & -0.01 \\
\hline Mother has excellent health & 18.04 & -9.86 & -6.28 & -1.82 & -0.08 \\
\hline Father has excelleent health & 5.20 & -3.08 & -1.67 & -0.44 & -0.02 \\
\hline Mother's depression scale & 0.90 & -0.54 & -0.29 & -0.07 & 0.00 \\
\hline Father deppression scale & 2.27 & -1.36 & -0.72 & -0.18 & -0.01 \\
\hline Mother has a warm parenting & 6.10 & -3.52 & -2.02 & -0.54 & -0.02 \\
\hline Father has a warm parenting style & 2.79 & -1.66 & -0.89 & -0.23 & -0.01 \\
\hline
\end{tabular}


Figure 1: Probability of health status (Random effects odered probit)

(a) Basic covariates

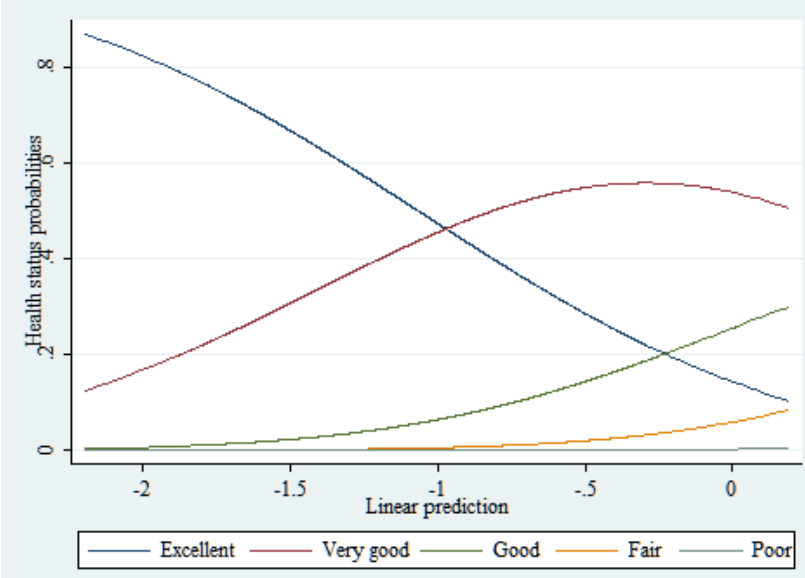

(b) Extended covariates

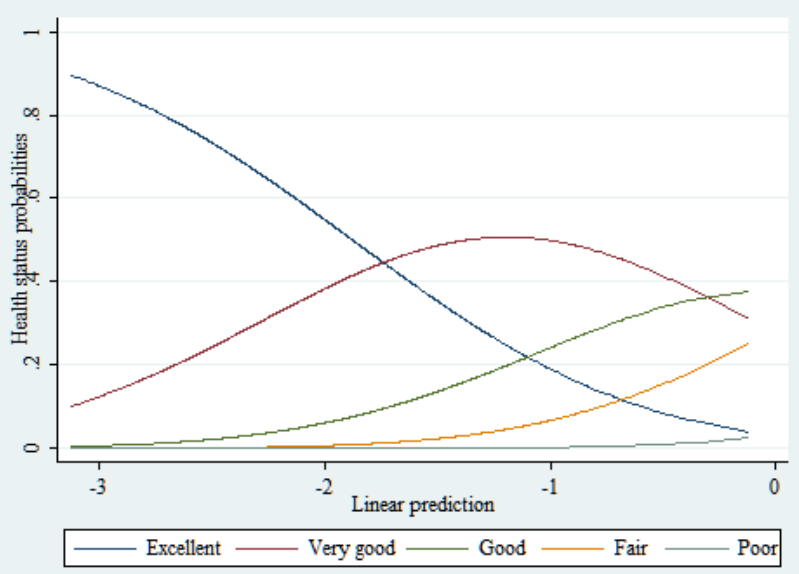

of health production, which predicts that paid maternity leave is expected to have a positive effect on child health by increasing maternity time available to care for children. This result is also consistent with previous literature (see for example, Baker and Milligan,2008a). However, when control for parental health in the extended covariates, this relationship is no longer statistically significant for asthma. Surprisingly our results show that paid paternity leave is positively associated with asthma and bronchiolitis. One possible explanation of this result could be that poor initial health (e.g. low birthweights) of these children induce father of these children to take leave, they might not have taken any leave, if their children are healthy. The probability of a child being up-to-date with its immunisation schedule is also significantly lower among children from households where parents took no leave around the child's birth. The probability of being immunized reduced by 24 and 22 percentage points for basic and extended covariates respectively, if parents had no access to any kind of leave. The results remain consistent when we control for parental health in the extended specification, which is in line with the findings of Daku et al. (2012). Likewise, the probability that the child was breastfed at one and six months increases significantly with the duration of maternity leave whether or not the leave was paid. Children from mothers with no maternity leave were significantly less likely to be breastfed at both one and six months. Our results show that the probability of breastfeeding at one month and 6 months increases by 2 and 0.6 percentage points, if mothers took paid leave. This result remain same when parental health is included in the extended set of covariates. This result about breastfeeding are consistent with the findings of Berger et al. (2005), Baker and Milligan (2008b), Cooklin et al. (2012) and Huang \& Yang (2014). 
Table 4: Effects of parental leave on chronic conditions and postnatal care (random effects probit model)

\begin{tabular}{|c|c|c|c|c|c|}
\hline $\begin{array}{l}\text { Selected } \\
\text { variables }\end{array}$ & Bronchiolitis & Asthma & $\begin{array}{r}\text { Fully } \\
\text { immunized } \\
\end{array}$ & $\begin{array}{l}\text { Breastfeeding } \\
\text { at one month }\end{array}$ & $\begin{array}{l}\text { Breastfeeding } \\
\text { at six months }\end{array}$ \\
\hline \multicolumn{6}{|l|}{ Basic covariates } \\
\hline \multicolumn{6}{|l|}{ Paid parental leave } \\
\hline Mother's leave & $* * * . .011$ & $*_{-.005}$ & -.002 & $* * * .021$ & $* * .006$ \\
\hline Father's leave & $* * * .022$ & **.014 & -.010 & $* * * .024$ & $*_{-} .013$ \\
\hline Mother $\times$ Father leave & $*_{-.001}$ & -.001 & $* * .003$ & $* * *_{-} .004$ & .001 \\
\hline \multicolumn{6}{|l|}{ All leave ${ }^{a}$} \\
\hline Mother's leave & $* * *_{-.005}$ & $*^{*} *_{-} .003$ & .001 & $* * * .007$ & ***.006 \\
\hline Father's leave & -.001 & .001 & -.001 & .003 & -.002 \\
\hline Mother $\times$ Father leave & .000 & -.000 & .000 & -.000 & .000 \\
\hline No leave $(1=y e s)$ & -.021 & .042 & $* * *-.236$ & $* * *-.090$ & $* * *-.188$ \\
\hline \multicolumn{6}{|l|}{ Extended covariates } \\
\hline \multicolumn{6}{|l|}{ Paid parental leave } \\
\hline Mother's leave & $*_{-}^{*} .011$ & -.002 & .001 & ***.020 & $* * .006$ \\
\hline Father's leave & $* * * .021$ & *.012 & -.008 & $* * * .030$ & -.008 \\
\hline Mother $\times$ Father leave & $*_{-.001}$ & -.000 & $* * .004$ & $* * *_{-} .004$ & .001 \\
\hline \multicolumn{6}{|l|}{ All leave ${ }^{a}$} \\
\hline Mother's leave & $*^{*} *_{-.004}$ & $*_{-} .003$ & .003 & $* * * .006$ & $* * * .005$ \\
\hline Father's leave & .001 & .000 & .002 & .002 & -.002 \\
\hline Mother $\times$ Father leave & -.000 & -.000 & -.000 & -.000 & .000 \\
\hline No leave $(1=y e s)$ & -.022 & .026 & $* * *_{-} .219$ & ****.099 & $* * *_{-.} .168$ \\
\hline
\end{tabular}

The LSAC data also has data on the duration of breastfeeding, which is collected from the question "How old was child when he/she completely stopped being breastfed? (Include expressed breast milk) (Age in days)". Interpreted literally, the results suggest that one additional week of maternity leave during is associated with an additional 0.4 day of breast-feeding, regardless of whether or not the leave is paid.The duration of father's leave during child birth has no significant association with the duration of breastfeeding, but the educational attainment of the parents does have a statistically significant association with the breastfeeding duration. For instance, compared with those mothers who did not completed high school, mothers with graduate degree has breastfed their children for 25 more days while mothers with postgraduate degree breastfed for 30 days longer. The level of education of the father also has strong and statistically significant effects on the duration of breast feeding: children of fathers who completed Year 12 were breastfed 7 days longer than children whose fathers did not complete Year 12. Children of fathers with graduate and postgraduate degrees were fed 18 and 15 days longer, respectively, than children whose father did not complete high school. Other important factors affecting the duration of breastfeeding include household characteristics: whether English sopken at home and both biological parents live in the 
Table 5: Effects of parental leave on the duration of breasfeeding

\begin{tabular}{lrrrr}
\hline \multirow{2}{*}{ Parameters } & \multicolumn{2}{c}{ Paid leave } & \multicolumn{2}{c}{ All leaves } \\
\cline { 2 - 5 } & Coef. & Std. err & Coef. & Std. err \\
\hline Mother's leave (weeks) & $* 0.40$ & 0.22 & $* * * 0.36$ & 0.07 \\
Father's leave (weeks) & 0.06 & 0.41 & 0.04 & 0.15 \\
Mother $\times$ Father's leave & -0.08 & 0.05 & -0.00 & 0.00 \\
Log of household income & 1.69 & 3.34 & 1.59 & 3.33 \\
Child's age (month) & -0.04 & 0.47 & -0.03 & 0.47 \\
Mother complete Year 12 & 3.74 & 3.90 & 3.40 & 3.88 \\
Mother has graduate degree & $* * * 25.03$ & 3.59 & $* * * 23.66$ & 3.55 \\
Mother has postgraduae degree & $* * * 29.99$ & 5.35 & $* * * 30.30$ & 5.32 \\
Father complete Year 12 & $* * 7.45$ & 3.38 & $* * 7.50$ & 3.36 \\
Father has graduate degree & $* * * 23.86$ & 3.89 & $* * * 22.83$ & 3.87 \\
Father has postgraduae degree & $* * * 18.54$ & 6.15 & $* * * 16.44$ & 6.12 \\
English spoken at home & $* * * 14.96$ & 5.59 & $* * 13.20$ & 5.57 \\
Both parents are at home & $* * * 24.95$ & 8.55 & $* * * 23.34$ & 8.51 \\
Constant & $* * *-188.42$ & 41.63 & $* * *-198.01$ & 41.46 \\
\hline Note: Only key variables are presented. ${ }^{* * *},{ }^{* *}$ and ${ }^{*}$ present significant at $1 \%, 5 \%$ and $10 \%$ level, respectively.
\end{tabular}

same house. In particular, children living in English-speaking households were breastfed for 15 days more than children from non English-speaking households, while households in which both biological parents are present breastfed their chilren for 25 days more than households with an absent biological parent.

\subsection{Robustness test}

In this section we check the robustness of our results when poential endogeneity of parental leave is ignored. The results of this biased estimator suggests that maternity leave has no significant effect on the reported health status of the child. Also, the health of children from mothers who did not take maternity leave is not significantly diffeerent to that of children whose mothers did take leave. We also test for effects of parental leave on other health indicator such as obesity, which is defined as having body mass index at 95 percentile of the distribution or higher. We also found no significant effects of parental leave on the probability of having an obese child, although the sign of paid leave for both mothers and fathers leave are, as expected, negative. The effects of mother's and father's paid leave deminish when both parents took leave. Finally, we examine the relationship between parental leave and the probability of having long-term condition as report by the mother. Maternity leave is negatively associated with the probability of having a long-term condition but statisticall significant results arise only when all types of leave are taken into account. 
Table 6: Effects of parental leave (naive estimate)

\begin{tabular}{|c|c|c|c|c|}
\hline \multirow{2}{*}{$\begin{array}{l}\text { Selected } \\
\text { variables }\end{array}$} & \multicolumn{2}{|c|}{ Basic covariates } & \multicolumn{2}{|c|}{ Extended covariates } \\
\hline & $\begin{array}{r}\text { Paid parental } \\
\text { leave }\end{array}$ & All leave $^{a}$ & $\begin{array}{r}\text { Paid parental } \\
\text { leave }\end{array}$ & All leave $^{a}$ \\
\hline \multicolumn{5}{|l|}{ Effects to child health } \\
\hline Mother's leave (weeks) & -0.001 & 0.0004 & 0.001 & 0.001 \\
\hline Father's leave (weeks) & $* * 0.01$ & 0.0018 & 0.01 & 0.01 \\
\hline Mother $\times$ Father leave & $*-0.001$ & -0.00002 & -0.001 & -0.0001 \\
\hline \multicolumn{5}{|l|}{ Effects to child obesity } \\
\hline Mother's leave (weeks) & -0.01 & 0.001 & *-0.020 & -0.0006 \\
\hline Father's leave (weeks) & -0.01 & 0.01 & -0.02 & 0.0030 \\
\hline Mother $\times$ Father leave & $* 0.003$ & -0.00003 & $* * 0.005$ & 0.0001 \\
\hline \multicolumn{5}{|l|}{ Effects to long-term } \\
\hline \multicolumn{5}{|l|}{ condition } \\
\hline Mother's leave (weeks) & -0.001 & $* *_{-0.01}$ & -0.002 & $* * *-0.01$ \\
\hline Father's leave (weeks) & 0.02 & -0.004 & 0.03 & -0.003 \\
\hline Father leave & -0.01 & 0.0002 & -0.01 & 0.0002 \\
\hline \multicolumn{5}{|c|}{$\begin{array}{l}\text { Note: Basic Covariates include child's age, gender,child's previous health status, family income, parents' age and education, } \\
\text { family income, household size, English spoken at home, Aboriginal and Torres Strait Islanders status, presence of both parents } \\
\text { at home; Extended covariates include basic covariates plus parents' mental and physical health, parenting style. Other covariates } \\
\text { are mostly insignificant and are not reported for brevity. Significance levels: } * * * 1 \%, * *=5 \% \text { and }{ }^{*}=10 \% ; \text { all leave includes } \\
\text { paid parental leave, unpaid parental leave, recreation leave, long service leave, sick leave and other leave taken around childbirth. } \\
\text { To interpret the coefficient as marginal effects one would need to multiply them with the probability density function, which is } \\
\text { less than one, of the interested outcomes. Thus, the parameters can be loosely interpreted as the upper bound of the marginal } \\
\text { effects. }\end{array}$} \\
\hline
\end{tabular}

\section{Conclusions}

One of the main goals of the recent Australia's first paid national parental leave scheme was to increase the welfare of children, which can be achieved by parental time off from work around child birth. This is motivated by the fact that the first months and years in a child's life are crucial for his/her future development. The reasons that increased parental leave might benefit children include: prolonged breastfeeding, up-to-date immunisation and other positive effects on child health. The work presented here does produce support for some of these hypotheses. Our results indicate that children whose mothers took maternity leave are less likely to have asthma and bronchiolitis and more likely to be breastfed. The positive association between paid maternity leave, breasfeeding and bronchiolitis is also robust to changes in the specification of the model (e.g., the inclusion of extended covariates). Another robust result of this paper is that children are significantly less likely to be immunized and or breastfed when the parents report taking no leave in connection with their child's birth. Thus, our empirical work for Australia confirms many aspects of the potential benefits for parental leave for children, even for the very young children in our sample. Given the relevance of this topic to the economy, including labour markets, welfare and 
health, work on the longer-term consequences of these benefits will, when possible, also provide further policy insights.

\section{References}

Australian Institute of Family Studies. 2007. Longitudinal Study of Australian Children, Wave 2 Data Release. Australian Institute of Family Studies, Melbourne. www.aifs.gov.au/growingup.

Baird, M. 2004. Orientations to paid maternity leave: Understanding the Australian debate. Journal of Industrial Relations, 46(3), 259-274.

Baker, M., \& Milligan, K. 2008a. Evidence from maternity leave expansions of the impact of maternal care on early child development. Tech. rept.

Baker, M., \& Milligan, K. 2010. Evidence from maternity leave expansions of the impact of maternal care on early child development. Journal of Human Resources, 45(1), 1-32.

Baker, Michael, \& Milligan, Kevin. 2008b. Maternal employment, breastfeeding, and health: evidence from maternity leave mandates. Journal of Health Economics, 27(4), 871-887.

Baxter, Jennifer. 2009. Mothers' timing of return to work by leave use and pre-birth job characteristics. Journal of Family Studies, 15(2), 153-166.

Berger, Lawrence M., Hill, Jennifer, \& Waldfogel, Jane. 2005. Maternity leave, early maternal employment and child health and development in the US. The Economic Journal, 115(501), F29 - F47.

Berger, L.M., \& Waldfogel, J. 2004. Maternity leave and the employment of new mothers in the United States. Journal of Population Economics, 17(2), 331-349.

Brooks-Gunn, J., Han, W.J., \& Waldfogel, J. 2002. Maternal employment and child cognitive outcomes in the first three years of life: The NICHD study of early child care. Child Development, 73, 1052-1072.

Carro, J.M. 2007. Estimating dynamics panel data discrete choice model models with fixed effects. Journal of Econometrics, 140(2), 503-528.

Chamberlain, G. 1980. Analysis of Covariance with Qualitative Data. Review of Economic Studies, 47, $225-238$. 
Contoyannis, P., Jones, A.M., \& Rice, N. 2004. The Dynamics of Health in the British Household Panel Survey. Journal of Applied Econometrics, 19(4), 473-503.

Contoyannis, Paul, \& Li, Jinhu. 2011. The evolution of health outcomes from childhood to adolescence. Journal of Health Economics, 30, 11-32.

Cooklin, Amanda R, Rowe, Heather J, \& Fisher, Jane RW. 2012. Paid parental leave supports breastfeeding and mother-infant relationship: a prospective investigation of maternal postpartum employment. Australian and New Zealand journal of public health, 36(3), 249-256.

Daku, Mark, Raub, Amy, \& Heymann, Jody. 2012. Maternal leave policies and vaccination coverage: A global analysis. Social Science 63 Medicine, 74(2), 120-124.

Dustmann, Christian, \& Schonberg, Uta. 2012. Expansions in maternity leave coverage and children's long-term outcomes. American Economic Journal: Applied Economics, 4(3), 190-224.

Ferrer-i Carbonell, Ada, \& Frijters, Paul. 2004. How Important is Methodology for the Estimate of the Determinants of Hapiness? The Economic Journal, 114, 641-659.

Glezer, H. 1988. Maternity leave in Australia: employee and employer experiences: report of a survey. Australian Institute of Family Studies, Melbourne.

Greene, H. William. 2008. Econometric analysis. 6th edn. Upper Saddle River, N.J.: Pearson/Prentice Hall.

Gregg, Paul, \& Waldfogel, Jane. 2005. Symposium On Parental Leave, Early Maternal Employment And Child Outcomes: Introduction. The Economic Journal, 115(501), F1 - F6.

Gregg, Paul, Washbrook, Elizabeth, Propper, Carol, \& Burgess, Simon. 2005. The Effects of a Mother's Return to Work Decision on Child Development in the UK. The Economic Journal, 115(501), F48 F80.

Grossman, M. 2000. Handbook of Health Economics. North Holland. Chap. The Human Capital Model, pages $347-408$.

Grossman, Michael. 1972. On the Concept of Health Capital and the Demand for Health. Journal of Political Economy, 82(2), 223-255.

Haines, Michael R, \& Kintner, Hallie J. 2008. Can breast feeding help you in later life? Evidence from German military heights in the early 20th century. Economics $\& 3$ Human Biology, 6(3), 420-430. 
Han, W., Waldfogel, J., \& Brooks-Gunn, J. 2001. The effects of maternal employment on children of the National Longitudinal Survey of Youth. Developmental Psychology, 35, 445-459.

HREOC. 2002. Valuing Parenthood, Options for Paid Maternity Leave: Interim Paper. Tech. rept. Human Rights and Equal Opportunity Commission, Sydney.

Huang, Rui, \& Yang, Muzhe. 2014. Paid maternity leave and breastfeeding practice before and after California's implementation of the nation's first paid family leave program. Economics $\&$ Human Biology.

Jacobson, L. 2000. The family as producer of health-an extended Grossman model. Journal of Health Economics, 19(5), 611-637.

Jones, Andrew M, \& Schurer, Stefanie. 2011. How does heterogeneity shape the socioeconomic gradient in health satisfaction? Journal of Applied Econometrics, 26(4), 549-579.

Khanam, Rasheda, Nghiem, Hong Son, \& Connelly, Luke B. 2009. Child Health and the Income Gradient: Evidence from Australia. Journal of Health Economics, 28, 805-817.

Kintner, Hallie J. 1988. The impact of breastfeeding patterns on regional differences in infant mortality in Germany, 1910. European Journal of Population/Revue européenne de Démographie, 3(2), 233-261.

Kuhn, J., Zirngibl, A., Wildner, M., Caselmann, W. H., \& Kerscher, G. 2006. [Regional mortality differences in Bavaria]. Gesundheitswesen, 68(8-9), 551-556.

Mundlak, Y. 1978. On the Pooling of Time Series and Cross Section Data. Econometrica, 46, 69-85.

Murnane, Richard J, \& Willett, John B. 2010. Methods matter: Improving causal inference in educational and social science research. Oxford University Press.

Propper, Carol, Rigg, John, \& Burgess, Simon. 2007. Child health: evidence on the roles of family income and maternal mental health from a UK birth cohort. Health Economics, 16(11), 1245-1269.

Rasmussen, A.W. 2010. Increasing the length of parents' birth-related leave: The effect on children's long-term educational outcomes. Labour Economics, 17(1), 91-100.

Reid, Alice. 2002. Infant feeding and post-neonatal mortality in Derbyshire, England, in the early twentieth century. Population studies, 56(2), 151-166. 
Rossin, Maya. 2011. The effects of maternity leave on children's birth and infant health outcomes in the United States. Journal of Health Economics, 30(2), 221-239.

Ruhm, C. J. 2000. Parental leave and child health. Journal of Health Economics, 19(6), 931-960.

Ruhm, C.J. 2004. Parental employment and child cognitive development. Journal of Human Resources, 39(1), 155-192.

Soloff, Carol, Lawrence, David, \& Johnstone, Robert. 2005. LSAC Technical Paper No. 1: Sample design. Tech. rept. Australian Institute of Family Studies, Melbourne, Australia.

Tanaka, Sakiko. 2005. Parental leave and child health across OECD countries. The Economic Journal, 115(501), F7 - F28.

Waldfogel, Jane, Han, Wen-Jui, \& Brooks-Gunn, Jeanne. 2002. The effects of early maternal employment on child cognitive development. Demography, 39(2), 369-392.

Whitehouse, G., Baird, M., \& Diamond, C. 2005. The Parental Leave in Australia Survey. Australian Institute of Family Studies. Longitudinal Study of Australian Children Wave 1.5 Infant Mailback Questionnaire, Section B-F: 2-8.

Whitehouse, G., Baird, M., Diamond, C., \& Hosking, A. 2006. The Parental Leave in Australia Survey: November 2006 Report.

Whitehouse, G, Baird, M, Diamond, C, \& Soloff, C. 2007a. Parental Leave in Australia: Beyond the Statistical Gap. Journal of Industrial Relations, 49(1), 103-112.

Whitehouse, Gillian, Diamond, Chris, \& Baird, Marian. 2007b. Father's use of Leave in Australia. Community, Work and Family, 10(4), 387-407.

Whitehouse, Gillian, Hosking, Amanda, \& Baird, Marian. 2008. Returning too soon? Australian mothers' satisfaction with maternity leave duration. Asia Pacific Journal of Human Resources, 46(3), 288-302.

Winegarden, CR, \& Bracy, P.M. 1995. Demographic consequences of maternal-leave programs in industrial countries: evidence from fixed-effects models. Southern Economic Journal, 61(4), 1020-1035.

Woodbury, Robert Morse. 1926. Infant mortality and its causes. Williams \& Wilkins. 